\title{
TUMORS AND TUMOR-LIKE LESIONS OF THE SALIVARY GLANDS: MORPHOLOGICAL CHARACTERISTICS OF THE SURGICAL MATERIAL
}

DOI: 10.36740/WLek202104122

\author{
Igor S. Brodetskyi', Vladislav A. Malanchuk', Bogdan V. Sorokin², Mykhailo S. Myroshnychenko ${ }^{3}$, Yuliya I. Beketova ${ }^{2}$, \\ Olena 0. Dyadyk², Nataliia V. Kapustnyk ${ }^{3}$, Mykhailo S. Krotevych", Sergey B. Brodetskyi ${ }^{5}$ \\ 'BOGOMOLETS NATIONAL MEDICAL UNIVERSITY, KYIV, UKRAINE \\ 2SHUPYK NATIONAL HEALTHCARE UNIVERSITY OF UKRAINE, KYIV, UKRAINE \\ ${ }^{3}$ KHARKIV NATIONAL MEDICAL UNIVERSITY, KHARKIV, UKRAINE \\ "NATIONAL CANCER INSTITUTE, KYIV, UKRAINE \\ ${ }^{5}$ TARAS SHEVCHENKO NATIONAL UNIVERSITY OF KYIV, KYIV, UKRAINE
}

\begin{abstract}
The aim is to give a morphological characteristic of tumors and tumor-like lesions of the salivary glands in the course of a comprehensive analysis of the surgical material. Materials and methods: The study used surgical material from 67 patients with various pathologies of the salivary glands. The patients were treated at Kyiv City Clinical Hospital No. 12 (Ukraine, Kiev) from 2014 to 2018. The resulting material was fixed in a 10\% solution of neutral formalin (pH 7.4) for 24-48 hours, carried out according to the generally accepted technique and embedded in paraffin. Serial sections $2 \mu \mathrm{m}$ thick were made from paraffin blocks and stained with hematoxylin and eosin. Microspecimens were studied, using Olympus BX-41 microscope (Japan).

Results: A comprehensive morphological study of the surgical material of patients with salivary gland pathology undergoing treatment at Kyiv City Clinical Hospital No. 12 (Ukraine, Kiev) for the period from 2014 to 2018 revealed benign tumors and tumor-like lesions of these glands. Pleomorphic adenomas and adenolymphomas represented benign tumors of the salivary glands, while cysts represented tumor-like lesions.

Different ratios of parenchymal and stromal components characterized pleomorphic adenomas of the salivary glands. On this basis, we identified three tumor variants (mesenchymal (15 cases, $50.0 \%)$; mixed or classic (10 cases, $33.3 \%)$; epithelial (5 cases, $16.7 \%)$ ). A characteristic microscopic feature of salivary gland adenolymphomas was a pronounced predominance of the parenchyma over the stroma. A well-defined wall, represented by connective tissue fibers and epithelial lining, characterized the cysts of the salivary glands. The connective tissue capsule separating the tumor tissue from the intact tissue of the salivary gland was clearly pronounced in adenolymphomas, and in pleomorphic adenomas it could be clearly expressed, intact, with tumor invasion or absent. In mesenchymal and mixed variants of pleomorphic adenomas, in comparison with the epithelial variant, there was a frequent tumor invasion of the capsule, thinning of the capsule or its absence.

Conclusions: Morphological examination of the surgical material allows us to diagnose tumors (pleomorphic adenomas and adenolymphomas) and non-tumor lesions (cysts) of the salivary glands. This, of course, is of great therapeutic, diagnostic and prognostic value. Among the identified pathology of the salivary glands, pleomorphic adenomas cause certain difficulties in morphological diagnosis due to their structural diversity and heterogeneity, sometimes requiring morphometric, immunohistochemical or genetic research.
\end{abstract}

KEY WORDS: tumors, tumor-like lesions, salivary glands, surgical materials, morphology

Wiad Lek. 2021;74(4):929-933

\section{INTRODUCTION}

Saliva, produced by salivary glands, is a complex mixture of fluid, electrolytes, enzymes, and macromolecules. They function together and perform several important roles: lubrication to aid in swallowing and digestion; digestion of starches with salivary amylase; modulation of taste; protection against dental caries; and defense against pathogens [1]. The salivary glands are the paired parotid, submandibular and lingual glands alongside several hundred minor salivary glands, distributed through the upper aerodigestive system [2].

Many diseases, both local and systemic, can affect the salivary glands. Prevailing salivary gland diseases depend on various etiological factors. Small stones formed in the gland ducts can block the glands. Viral, bacterial, or (rarely) fungal agents may infect the glands or they may be the targets of autoimmune attacks, affecting their functions. In the salivary glands, benign and malignant tumors can develop [3]. Tumor-like lesions can also develop in the salivary glands [4].

At present, there are special methods diagnosing diseases of the salivary glands along with the questioning of the patient, examination and palpation of the affected area. These are: echography, thermal visiography, sialometry, scintigraphy and radionuclide scanning, radiography of the salivary gland, using radiopaque substances, and computed 


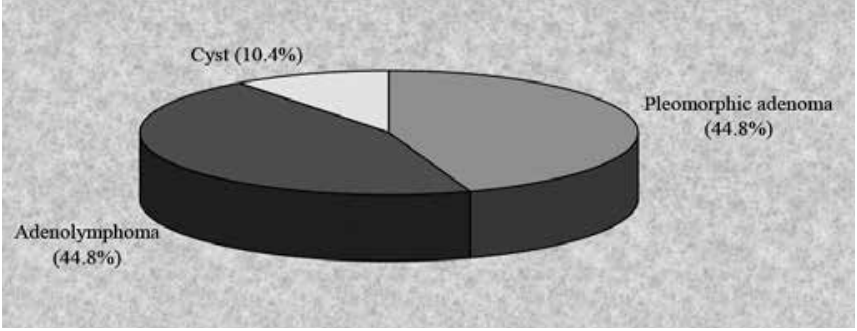

Fig. 1. The survey microscopy results of the studied cases.

tomography [5]. Despite the available arsenal of methods for diagnosing pathology of the salivary glands, the percentage of diagnostic errors, according to our data and the data of other scientists, varies from $46 \%$ to $70 \%$ [6].

In patients with pathology of the salivary glands the choice of treatment method, planning of the nature and volume of surgical intervention in most cases depends on the results of morphological examination.

\section{THE AIM}

The aim is to give a morphological characteristic of tumors and tumor-like lesions of the salivary glands in the course of a comprehensive analysis of the surgical material.

\section{MATERIALS AND METHODS}

The study used surgical material from 67 patients with various pathologies of the salivary glands. The patients were treated at Kyiv City Clinical Hospital No. 12 (Ukraine, Kiev) from 2014 to 2018 . The resulting material was fixed in a $10 \%$ solution of neutral formalin ( $\mathrm{pH} 7.4$ ) for $24-48$ hours, carried out according to the generally accepted technique and embedded in paraffin. Serial sections $2 \mu \mathrm{m}$ thick were made from paraffin blocks and stained with hematoxylin and eosin. Microspecimens were studied, using Olympus BX-41 microscope (Japan).

\section{RESULTS AND DISCUSSION}

Diagnosis of tumor and non-tumor diseases of the salivary glands is sometimes difficult and requires an interdisciplinary approach. Morphological examination of the salivary gland has an important therapeutic, diagnostic and prognostic value.

Detailed survey microscopy of all studied cases (fig. 1) in 60 cases $(89.6 \%)$ revealed benign tumors of the salivary glands, represented by pleomorphic adenoma (30 cases, $44.8 \%$ ) and adenolymphoma (30 cases, $44.8 \%$ ). Cysts of the salivary glands were diagnosed in 7 cases $(10.4 \%)$.

In our earlier research, we identified morphological features of all cases of pleomorphic adenomas [7]. It was noted that these tumors were characterized by structural diversity and heterogeneity, different ratios of parenchymal (epithelial) and mesenchymal (stromal) components. Based on this, we identified three histological variants of the tumor. In 15 cases (50.0\%), a mesenchymal variant was found, characterized by a predominance of the stroma over the parenchyma (fig. 2). Mixed or classic variant of the tumor was identified in 10 cases $(33.3 \%)$, characterized by an almost equal content of stroma and parenchyma. An epithelial variant was determined in 5 cases $(16.7 \%)$ with prevalence of parenchyma over the stroma (fig. 3).

In pleomorphic adenomas, epithelial and myoepithelial cells represented the parenchymal component. Epithelial cells were of various sizes and shapes (round, polygonal, cubic). In part of the visual fields, these cells were of the basaloid, spindle-cell, squamous, clear-cell, or plasmacytoid types. The epithelial component less commonly included mucous, sebaceous, serous or multinucleated cells. Accumulations of epithelial cells more often formed nests and cords, which anastomosed with each other, and less often - solid, trabecular, cystic, glandular, ductal or tubular structures.

We did not find myoepithelial cells in all studied cases, as they were focally located. In some places, these cells were tightly placed to each other, and in some places they were loose, had a polygonal or fusiform shape. In part of the visual fields, they resembled smooth muscle cells.

The stroma of pleomorphic adenomas showed connective tissue fibers, and vessels of various sizes were located between them. Moderate hemodynamic disturbances were revealed in the stroma of some tumors, characterized by edema, vascular congestion, and small focal diapedetic hemorrhages in the perivascular space. In all cases, we observed myxoid, chondroid and mucoid zones in the stroma of the tumor, while in isolated cases - osteoid zones and areas of lipomatosis.

Slow growth, scanty symptoms and a tendency to recurrence characterize pleomorphic adenoma of the salivary glands [8].

Recurrence of pleomorphic adenomas, according to many scientists, directly depends on the morphological state of the tumor capsule [9]. With the mesenchymal variant of the tumor, the capsule in 3 cases $(20.0 \%)$ was intact, in 4 cases $(26.7 \%)$ it was not detected, and in 8 cases $(53.3 \%)$ we noticed invasion of the tumor into the capsule. The tumor capsule in the mixed variant in 2 cases $(20.0 \%)$ was intact, in 4 cases ( $40.0 \%)$ it was not detected, in 4 cases $(40.0 \%)$ it was damaged due to tumor invasion. In the epithelial variant, the capsule in 1 case $(20.0 \%)$ was with tumor invasion, and in 4 cases $(80.0 \%)$ it looked intact.

Scientists also noted that the capsule of pleomorphic adenomas had thick, dense, fibrous tissue. In some cases, it was discontinuous, or absent or became invaded and even penetrated by a tumor. It was identified the correlation between capsular features and parenchymal/stromal ratio of the tumor. In series of cases hypercellular pleomorphic adenomas had a thick capsule while hypocellular tumors had a thin capsule [10].

Other researches emphasized absence of association between capsular features and histological subtype of pleomorphic adenomas [11].

Microscopically, in 30 cases, adenolymphoma of the salivary glands showed glandular and cystic cavities lined 


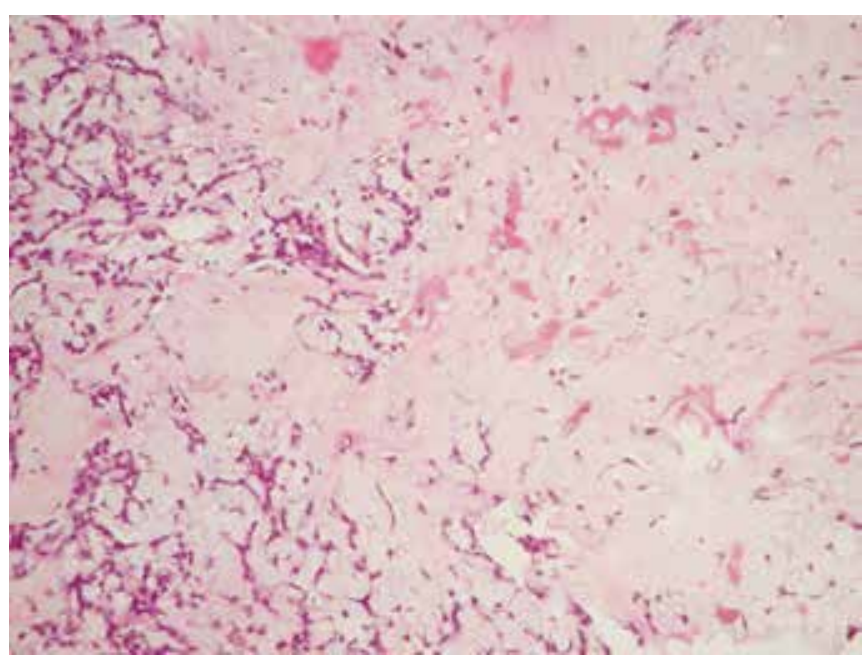

Fig. 2. Mesenchymal variant of pleomorphic adenoma. Hematoxylin and eosin staining, $\times 200$.

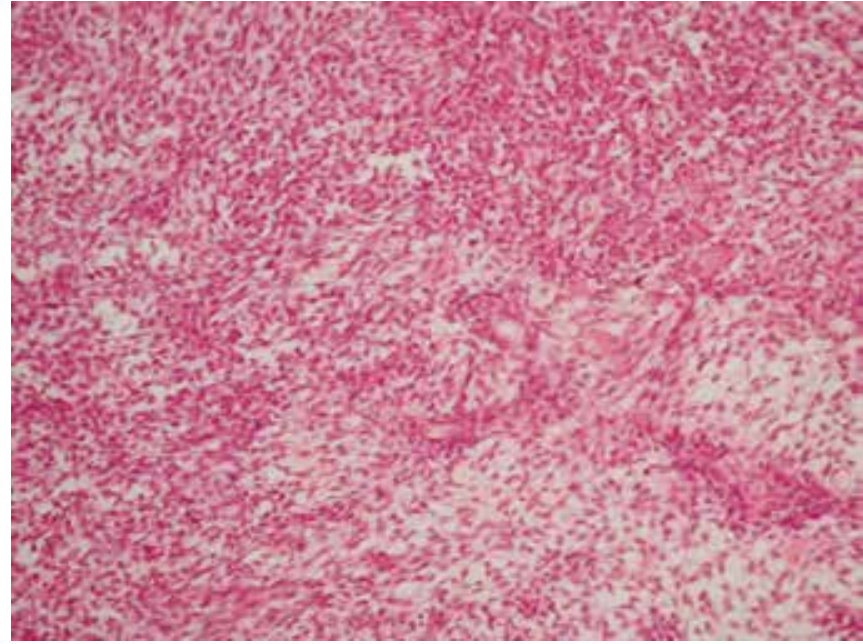

Fig. 3. Epithelial variant of pleomorphic adenoma. Hematoxylin and eosin staining, $\times 200$.
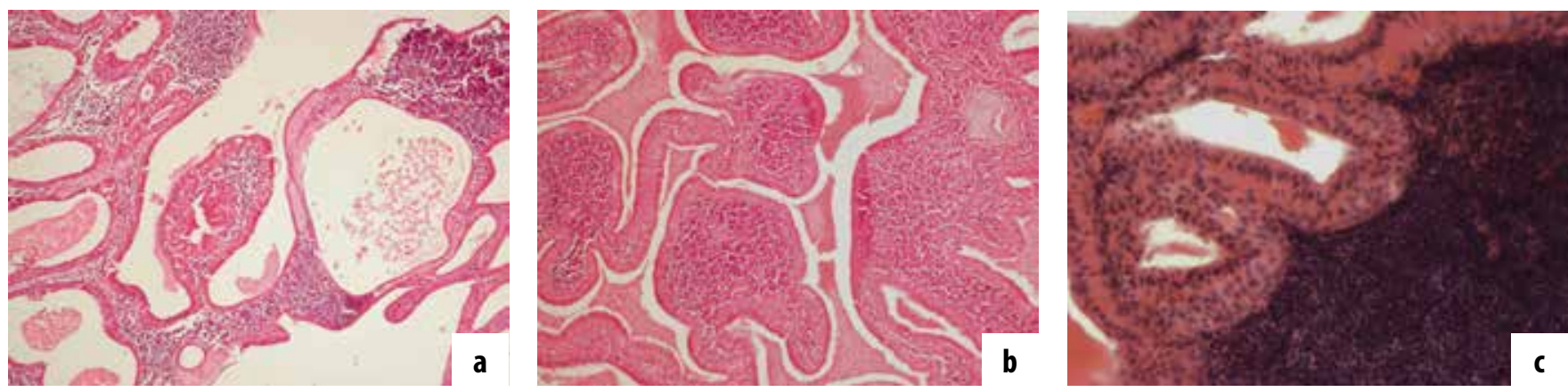

Fig. 4. Microscopic structure of adenolymphoma. Hematoxylin and eosin staining, a) $\times 100, b) \times 100, c) \times 400$.

with two-row epithelium (fig. 4). In all cases, we noticed the formation of papillary structures, protruded into the lumen of the cystic cavities. Eosinophilic contents were in the lumens of glandular and cystic-papillary structures. In 24 cases $(80.0 \%)$, eosinophilic contents with dystrophic altered epithelial cells were in the lumens of the cystic cavities. In 3 cases (10.0\%), the epithelial lining was not detected in some of the cystic cavities. In 1 case $(3.3 \%)$, an increase in the number of layers was determined in the epithelial layer, as a result of which it lost its characteristic two-layer structure. The tumor stroma had connective tissue fibers, vessels, pronounced lymphoid infiltration, which in a significant number of visual fields formed small and large lymphoid follicles with light centers. In all studied cases of the salivary glands adenolymphoma we noted, firstly, a pronounced predominance of the parenchymal component over the stromal one; secondly, a clear connective tissue capsule separating the tumor tissue from the intact tissue.

Recurrences of adenolymphomas of the salivary glands, according to the literature, are very rare and occur in connection with the multicentric growth of this tumor. Malignancy with adenolymphoma is also extremely rare [12].

Thus, in this study, benign tumors of the salivary glands represented by various histological variants of pleomorphic adenomas and adenolymphomas. The works of many sci- entists highlight, among all benign tumors of the salivary glands, a pronounced predominance of cases with pleomorphic adenomas and adenolymphomas [8].

Histogenesis of pleomorphic adenomas and adenolymphomas of the salivary glands is a controversial issue. The source of developing pleomorphic adenomas of the salivary glands can be epithelial cells lining the secretory sections and excretory ducts; myoepithelial cells containing secretory elements in the cytoplasm; stroma of the tumor $[13,14]$.

Many scientists associate the origin of adenolymphoma with the ducts of salivary glands epithelium. The lymphoid component of adenolymphoma derives from altered lymph nodes, or occurs secondarily due to a lesion in the epithelium, or a combination of both. Aside from B- and T-cells, the infiltrate also contains macrophages and mast cells, suggesting local presence of an antigen triggering immune cell recruitment [15].

Survey microscopy revealed cysts of the salivary glands in 7 cases, which, as is known, belong to tumor-like lesions [4].

In all the cases studied, the cyst wall of the salivary glands was represented by connective tissue fibers and epithelial lining (fig. 5, 6), which was thinned or not visible in single visual fields. In the cyst walls in 6 cases (85.7 \%) there was a moderately pronounced diffuse lymphoid-histiocytic infiltration, combined in 2 cases $(28.6 \%)$ with a few neutrophilic leukocytes. In 5 cases $(71.4 \%)$ moderate hemodynamic 


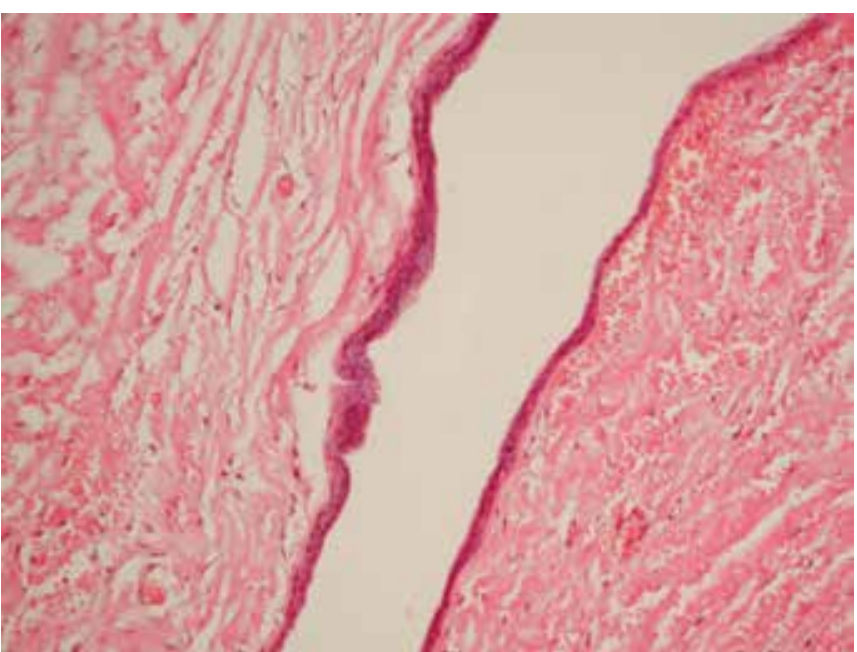

Fig. 5. The wall of the cyst of the salivary gland, represented by connective tissue fibers and epithelial lining. Moderate hemodynamic disturbances in the cyst wall. Hematoxylin and eosin staining, $\times 200$.

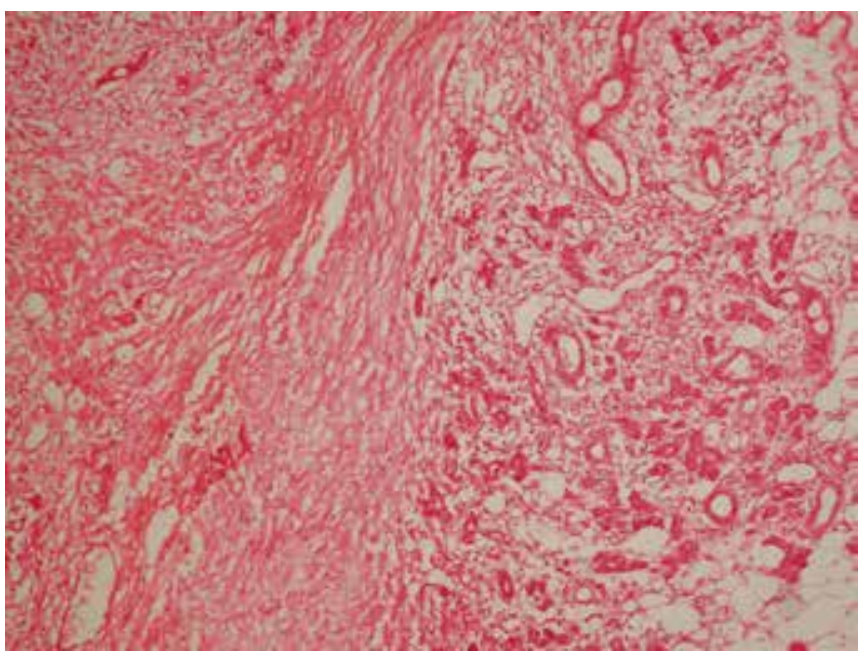

Fig. 6. Lymphoid-histiocytic infiltration with an admixture of a few neutrophilic leukocytes in the cyst wall and adjacent tissue of the salivary gland. Atrophic and sclerotic changes in the salivary gland tissue. Hematoxylin and eosin staining, $\times 200$.

disturbances were revealed, represented by edema, vascular congestion and small focal hemorrhages (fig. 5).

All cases revealed sclerotic changes with atrophy of the parenchymal component in the tissue of the salivary gland adjacent to the cysts. They combined with moderate diffuse lymphoid-histiocytic infiltration with an admixture of single neutrophilic leukocytes in 2 cases $(28.6 \%)$, in 6 cases $(85.7 \%)$ with hemodynamic changes, in 1 case $(14.3 \%)$ with small calculi in the excretory ducts (fig. 6). Thus, the tissue of the salivary glands adjacent to the cyst wall showed signs of chronic sialoadenitis.

The reasons for the formation of the salivary glands cysts can be obstruction of the salivary gland duct with a stone; compression and narrowing of the duct of the gland from the outside by a tumor or due to the excessive development of connective tissue (sclerosis). The latter, as is known, results from the inflammatory process caused by a damaging factor of various origins (biological, chemical, physical, mechanical, etc.).

Salivary gland cysts can also be of congenital origin. They develop from an accessory rudimentary duct detached during embryogenesis [16].

\section{CONCLUSIONS}

1. A comprehensive morphological study of the surgical material of patients with salivary gland pathology undergoing treatment at Kyiv City Clinical Hospital No. 12 (Ukraine, Kiev) for the period from 2014 to 2018 revealed benign tumors and tumor-like lesions of these glands. Pleomorphic adenomas and adenolymphomas represented benign tumors of the salivary glands, while cysts represented tumor-like lesions.

2. Morphological examination of the surgical material allowed us to diagnose tumor and non-tumor diseases of the salivary glands. This, of course, was of great therapeutic, diagnostic and prognostic value. Among the identified pathology of the salivary glands, pleomorphic adenomas caused certain difficulties in morphological diagnosis due to their structural diversity and heterogeneity, sometimes requiring morphometric, immunohistochemical or genetic research.

3. Different ratios of parenchymal and stromal components characterized pleomorphic adenomas of the salivary glands. On this basis, we identified three tumor variants (mesenchymal (15 cases, $50.0 \%$ ); mixed or classic (10 cases, $33.3 \%$ ); epithelial (5 cases, $16.7 \%)$ ). A characteristic microscopic feature of salivary gland adenolymphomas was a pronounced predominance of the parenchyma over the stroma. A well-defined wall, represented by connective tissue fibers and epithelial lining, characterized the cysts of the salivary glands.

4. The connective tissue capsule separating the tumor tissue from the intact tissue of the salivary gland was clearly pronounced in adenolymphomas, and in pleomorphic adenomas it could be clearly expressed, intact, with tumor invasion or absent. In mesenchymal and mixed variants of pleomorphic adenomas, in comparison with the epithelial variant, there was a frequent tumor invasion of the capsule, thinning of the capsule or its absence. The prospect for further research is to clarify the factors related to the etiopathogenesis of pleomorphic adenomas, adenolymphomas and cysts of the salivary glands may be favorable to the understanding and management of such human illnesses.

\section{REFERENCES}

1. Wilson KF, Meier JD, Ward PD. Salivary gland disorders. American Family Physician. 2014;89(11):882-888.

2. Rahayuningtyas $E D$, Setiadhi R. Virus as a cause of salivary gland diseases. ODONTO: Dental Journal.2019;6(1):37-43.

3. Sisto M. Special issue - «Diseases of the salivary glands». Journal of Clinical Medicine. 2020;9:3886. doi:10.3390/jcm9123886.

4. Kessler AT, Bhatt AA. Review of the major and minor salivary glands, part 2: neoplasms and tumor-like lesions. Journal of Clinical Imaging Science. 2018;8(48). doi: 10.4103/jcis.JCIS_46_18. 
5. Osipyan EM, Berezina AE, Galstyan MV, et al. Znachenie citomorfologicheskih issledovanij v diagnostike zabolevanij sljunnyh zhelez. Importance of cytomorphological studies in the diagnosis of salivary gland disorders. Medical News of the North Caucasus. 2011;2:44-48. (Ru).

6. Brodetskyi IS. Analiz klinichnogo ta patogistologichnogo diagnoziv hvoryh z novoutvorennjamy slynnyh zaloz za danymy arhivnyh istorij hvoryh kliniky NMU imeni 0.0. Bogomolcja v period 2014-2018 roky. Analysis of clinical and pathohistological diagnoses of patients with neoplasms of the salivary glands according to the archival histories of patients in the clinic of the 0.0. Bogomolets NMU in the period 20142018 years. Stomatological Bulletin. 2019;31(1):84-87. (Ua).

7. BrodetskyilS, Dyadyk00,Myroshnychenko MS,ZaritskaVI. Morphological characteristics of pleomorphic adenomas of salivary glands (analysis of the surgical material). Wiadomości Lekarskie.2020;73(11):2339-2344.

8. Speight PM, Barrett AW. Salivary gland tumours: diagnostic challenges and an update on the latest WHO classification. Diagnostic Histopathology. 2020;26(4):147-158.

9. Yaremenko Al, Kutukova SI, Harutyunyan, Petrov NL. Mozhno ly prognozyrovat recydyv pleomorfnoj adenomy? Analyz arhyvnyh dannyh pacyentov s pleomorfnoj adenomoj po dannym klynyky cheljustno-lycevoj hyrurgyy FGBOU VO PSPbGMU ym. Y.P. Pavlova MZ RF. Is it possible to predict the recurrence of pleomorphic adenoma? A systematic review of surgical treatment of patients with pleomorphic adenoma according maxillofacial surgery clinic of Pavlov First Saint-Petersburg State Medical University. Dental Institute. 2019;4:73-75. (Ru).

10. Guerra G, Testa D, Montagnani S, et al. Surgical management of pleomorphic adenoma of parotid gland in elderly patients: role of morphological features. International Journal of Surgery. 2014;12:S12-S16.

11. Lopes MLDd, Barroso KMA, Henriques ÁCG, et al. Pleomorphic adenomas of the salivary glands: retrospective multicentric study of 130 cases with emphasis on histopathological features. European Archives of Oto-rhinolaryngology. 2017; 274:543-551.

12. Liang CH, DiWY, Ren JP, et al. Imaging, clinical and pathological features of salivary gland adenolymphoma. European Review for Medical and Pharmacological Sciences. 2014;18:3638-3644.

13. Trandafirescu M, Cotuțiu C, Cojocaru E, Foia L. Immunohistochemical aspects in pleomorphic adenoma, related to its histogenesis and malignization. Romanian Journal of Oral Rehabilitation. 2012;4(4):11-16.
14. Almeslet AS. Pleomorphic adenoma: a systematic review. International Journal of Clinical Pediatric Dentistry. 2020: 10.5005/ jp-journals-10005-1776.

15. Porcheri C, Meisel CT, Mitsiadis TA. Molecular and cellular modelling of salivary gland tumors open new landscapes in diagnosis and treatment. Cancers. 2020;12: 3107. doi:10.3390/cancers12113107.

16. Porcheri C, Mitsiadis TA. Physiology, pathology and regeneration of salivary glands. Cells. 2019;8(976). doi:10.3390/cells8090976.

\section{ORCID and contibutionship:}

Igor S. Brodetskyi - 0000-0002-9434-4079 A,D,E,

Vladislav A. Malanchuk - 0000-0001-8111-0436 ${ }^{A, F}$

Bogdan V. Sorokin - 0000-0003-0511-7550 B,E

Mykhailo S. Myroshnychenko - 0000-0002-6920-8374 ${ }^{B, D}$

Yuliya I. Beketova - 0000-0001-8635-1802 B,C

Olena O. Dyadyk - 0000-0002-9912-4286 ${ }^{A, D}$

Nataliia V. Kapustnyk - 0000-0002-4875-398X E,F

Mykhailo S. Krotevych - 0000-0002-5228-7491 B,C

Sergey B. Brodetskyi - 0000-0002-6175-2797 D,E,F

\section{Conflict of interest:}

The Authors declare no conflict of interest.

\section{CORRESPONDING AUTHOR Mykhailo S. Myroshnychenko \\ Pathological Anatomy Department, Kharkiv National Medical University str. Svetlaya 27A, apt. 70, 61129, Kharkiv, Ukraine tel: $+380501699763,+380961033038$ \\ e-mail:msmyroshnychenko@ukr.net}

Received: 28.11 .2020

Accepted: 05.03 .2021

A - Work concept and design, B - Data collection and analysis, C - Responsibility for statistical analysis, D-Writing the article, $\mathbf{E}$ - Critical review, $\mathbf{F}$ - Final approval of the article 